\title{
Difference Analysis of Ecological Security Assessment Based on FAHP
}

\author{
Yahao Yin, Haihong $\mathrm{Li}^{*}$, and Fengqiu An \\ School of Environmental and Chemical Engineering, Xi'an Polytechnic University, Xi'an,710048, China.
}

\begin{abstract}
In this study, the important city of Guanzhong Plain-Weinan, was studied and its ecological security index changed from the year of 2000 to 2012. The stress-state-response (PSR) model was used to establish an ecological security assessment system based on agricultural development cities. The method of quantitative research including 12 indicators based on the fuzzy analytic hierarchy process (FAHP) model was constructed, and the main aspects such as the natural environment, economic society, and human activities were designed. The results showed that from 2000 to 2012, the area of ecological security and stability is gradually increasing, and the stability of the ecological environment is enhanced. The ecological security level in the central region of the country has developed well in the past 10 years, but the ecological security level in some areas has gradually increased in edge area.
\end{abstract}

\section{Introduction}

Regional ecological security is mainly affected by natural environmental factors and human social activities [1]. Land cover changes caused by human activities have a major impact on the climate, hydrothermal cycle, material energy exchange and biodiversity of the Earth's ecosystems, and play a decisive role in regional ecological security. The spatial and temporal changes in the assessment of regional ecological environment safety have become one of the hot issues in the study of global environmental change response [2].

Whether the ecological security assessment is accurate depends mainly on whether a reliable evaluation system can be established. Based on the conceptual framework of ecological security assessment, and using the PSR model, the thinking logic of "pressure-state-response" is used to highlight the interaction between human and environment [3]. Humans obtain the resources necessary for their survival and development from the natural environment, and change the natural resource reserves and environmental quality. But changes in nature and environmental conditions in turn affect human socioeconomic activities [4].

At present, there are many methods for processing ecological security evaluation data models. The methods for determining weights mainly include analytic hierarchy process (AHP) [5] and principal component analysis (PCA) [6]. According to the hierarchical and data characteristics of the selected indicators, considering the correlation between the data of this study, this study selects the FAHP to calculate the weight of the index. This method provides a quantitative evaluation index for selecting the optimal solution and has been widely used.

\section{Study area}

Wei Nan area contains 11 districts and is the main agricultural producing area of the Guanzhong Plain (see Figure1). Wei Nan is a warm temperate semi-humid and semi-arid monsoon climate. The annual average temperature in the area is $12.7 \sim 15.6{ }^{\circ} \mathrm{C}$. The annual precipitation is $390.7 \sim 592.2 \mathrm{~mm}$. The region is dominated by agricultural development, but the northeastern region of the region has abundant reserves of coal resources.

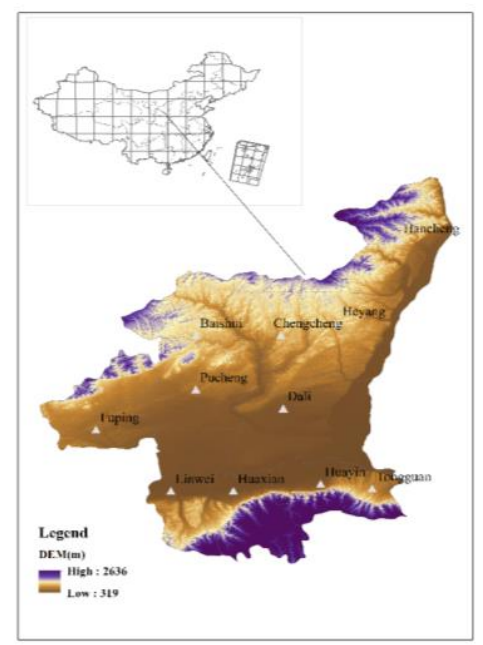

Fig. 1. The location of study area

\section{The index system}

The change of natural conditions is the direct influencing factor of ecological security. This study combines the

\footnotetext{
* Corresponding author: 1624116019@qq.com
} 
environmental characteristics of Wei Nan with external stress factors, including annual average precipitation, annual average temperature, annual average evaporation, sunshine hours, elevation and slope. Human beings are an extremely important part of the ecological environment. In this evaluation study, the reclamation rate, population density, road network density and natural growth rate per capita GDP and agricultural/industrial output value were selected.

\section{Data analysis model}

There are many different methods for determining the comprehensive weight of the evaluation index system at home and abroad [7]. The subjective empowerment method uses qualitative methods such as expert opinions and comprehensive consultation scores to determine the weights, and then comprehensively judges the dimensionless data. The Analytic Hierarchy Process (FAHP) is a multi-objective decision-making method combining qualitative and quantitative analysis, which was proposed by Saaty in the early 1970s [8].

In this paper, 12 evaluation indicators are selected from the target level, project level and indicator level. The coefficient of variation is used to determine the internal indicator weight of each component, and finally the ecological security comprehensive value (ESI) is calculated. The coefficient of variation and the weighting method for each indicator are as follows:

$$
E S I=\sum_{i=1}^{n}\left(W_{i} \times D_{i}\right)
$$

Among them, $\mathrm{Wi}$ is the weight value of each index, $\mathrm{Di}$ is the standardized value of each ecological security evaluation index, and $\mathrm{n}$ is the total number of indicators.

Table 1. Weights of the indicator system for ecological security assessment in southern Anhui

\begin{tabular}{|c|c|c|c|c|}
\hline $\mathbf{A}$ & B & Weight & $\mathrm{C}$ & Weight \\
\hline \multirow{12}{*}{$\begin{array}{l}\text { security } \\
\text { evaluatio } \\
\mathrm{n} \text { index }\end{array}$} & \multirow{5}{*}{$\begin{array}{c}\text { Natural cause } \\
\text { indicator }\end{array}$} & \multirow{6}{*}{0.3108} & elevation & 0.0154 \\
\hline & & & $\begin{array}{l}\text { average annual } \\
\text { precipitation }\end{array}$ & 0.0981 \\
\hline & & & $\begin{array}{c}\text { annual average } \\
\text { temperature }\end{array}$ & 0.0304 \\
\hline & & & $\begin{array}{l}\text { annual average } \\
\text { evaporation }\end{array}$ & 0.0928 \\
\hline & & & slope & 0.0648 \\
\hline & \multirow{5}{*}{$\begin{array}{l}\text { Social cause } \\
\text { indicator }\end{array}$} & & sunshine hours & 0.0093 \\
\hline & & \multirow{4}{*}{0.1958} & Reclamation rate & 0.0546 \\
\hline & & & Natural growth rate & 0.0141 \\
\hline & & & population density & \\
\hline & & & $\begin{array}{c}\text { road network } \\
\text { density }\end{array}$ & 0.1000 \\
\hline & $\begin{array}{c}\text { Economic } \\
\text { developme-nt }\end{array}$ & 0.4934 & $\begin{array}{c}\text { agricultural/in } \\
\text {-dustrial value ratio }\end{array}$ & 0.1645 \\
\hline & indicator & & per capita GDP & 0.3289 \\
\hline
\end{tabular}

\section{Results}

In 2000, Tongguan had the highest ecological security index, followed by Huayin and Huaxian, indicating that the ecological security index of these areas is relatively high.
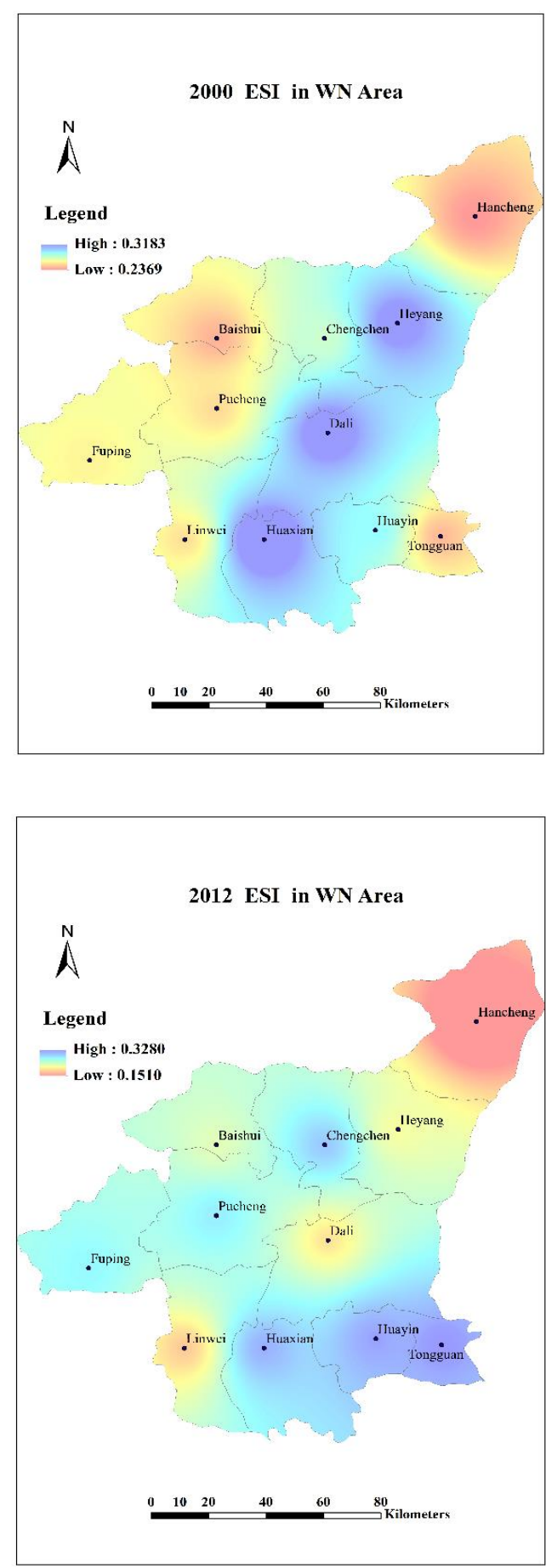

Fig. 2. Ecological security index chart of Wei Nan region The lowest ecological security index is Hancheng, followed by Linyi District and Dali, indicating that these areas have lower ecological security. In 2000, the region with a higher ecological security index was located in the middle of Weinan City, and the ecological security index in the marginal region was higher. In 2012, Huaxian had the highest ecological security index, followed by Daxie 
and Heyang, indicating that the ecological security index of these areas is relatively high. The lowest ecological security index is Hancheng, followed by Baishui and Shaoguan, indicating that the ecological security of these areas is low. In 2012, the region with a lower ecological security index was located in the northeastern part of Weinan City (Fig.2)

From 2000 to 2012, the ecological security index of Tongguan changed greatly and gradually developed towards instability. Hancheng was mainly the main producing area of coal mines. The mining of energy ore directly affected the stability of ecological security and had always been in a low ecological security state. The ecological security index of Linwei District has gradually increased, and ecological security had gradually stabilized.

From 2000 to 2012, the area of ecological security and stability is gradually increasing, and the stability of the ecological environment is enhanced. And the ecological security level in the central region of the country has developed well in the past 10 years, but the ecological security level in some areas has gradually increased in edge area.

\section{Conclusions}

Based on GIS technology, the PSR model framework was used to analyze the ecological security evaluation indicators of Weinan.The ecological security index of Tongguan changed greatly and gradually developed towards instability. Hancheng was mainly the main producing area of coal mines. The mining of energy ore directly affected the stability of ecological security and had always been in a low ecological security state. The ecological security index of Linwei District has gradually increased, and ecological security had gradually stabilized. From 2000 to 2012, the area of ecological security and stability is gradually increasing, and the stability of the ecological environment is enhanced.

\section{Acknowledgement}

This work was supported by the Science and Technology Department of Shaanxi Province under Grant number 2017GY-151, the Shaanxi Province "three Qin scholars" fund project, and the program funded by Shaanxi Provincial Education Department (No.18JK0354).

\section{References}

1. Xie $\mathrm{H}, \mathrm{He} \mathrm{Y}$, Xie $\mathrm{X}$. Exploring the factors influencing ecological land change for China's Beijing-Tianjin-Hebei Region using big data. $J$ Clean Prod, 142, 677-687, (2017).

2. Beniston, M. Climatic Change in Mountain Regions: A Review of Possible Impacts. Climatic Change, 59(1-2),5-31, (2003).

3. Niemeijer D, de Groot R S. Framing environmental indicators: moving from causal chains to causal networks. Environment development and sustainability, 10(1), 89-106, (2008).

4. Liu J, Dietz T, Carpenter S R, et al. Complexity of coupled human and natural systems. Science, 317,1513-1516, (2007).

5. Hou K, Li X, Wang J, et al. Evaluating Ecological Vulnerability Using the GIS and Analytic Hierarchy Process (AHP) Method in Yan'an, China. Pol $J$ Environ Stu, 25 (2016).

6. Hou K, Li X, jing Wang J, et al. An analysis of the impact on land use and ecological vulnerability of the policy of returning farmland to forest in Yan'an, China. Environ Sci Pollut R, 23, 4670-4680, (2016).

7. Singh R K, Murty H R, Gupta S K, et al. An overview of sustainability assessment methodologies. Ecol Indic, 15, 281-299, (2012).

8. Badri M A. Combining the analytic hierarchy process and goal programming for global facility location-allocation problem. Int J Prod Econ, 62, 237-248, (1999). 